\title{
Erratum to: No need for systemic heparinization during laparoscopic donor nephrectomy with short warm ischemia time
}

\author{
Frank Friedersdorff - Ingmar Wolff - Serdar Deger • Jan Roigas • \\ John Buckendahl - Hannes Cash • Markus Giessing - Lutz Liefeldt • \\ Kurt Miller · Tom Florian Fuller
}

Published online: 8 July 2011

(C) Springer-Verlag 2011

Erratum to: World J Urol

DOI 10.1007/s00345-011-0704-1

Unfortunately, the first name of one of the co-authors in the online published article is swapped. The correct first name is Tom Florian and the last name is Fuller.

The online version of the original article can be found under doi:10.1007/s00345-011-0704-1.

F. Friedersdorff · I. Wolff · S. Deger · J. Buckendahl ·

H. Cash · K. Miller · T. F. Fuller

Department of Urology, Charité Universitätsmedizin,

Berlin, Germany

M. Giessing

Department of Urology, Heinrich-Heine Universität,

Düsseldorf, Germany

L. Liefeldt

Department of Nephrology, Charité Universitätsmedizin,

Berlin, Germany

J. Roigas

Department of Urology, Vivantes Hospital, Berlin, Germany

F. Friedersdorff $(\square)$

Charitéplatz 1, 10117 Berlin, Germany

e-mail: frank.friedersdorff@charite.de 